\title{
Menstrual Hygiene Practices of Female Garment Workers
}

\author{
Article by M.M Aktaruzzaman ${ }^{1,}$ Irin Hossain ${ }^{2}$ \\ ${ }^{1} V B D C, D G H S$ \\ ${ }^{2}$ National Institute of Preventive and Social Medicine, Mohakhali, Dhaka \\ E-mail: irin.hossain@gmail.com
}

\begin{abstract}
Readymade garment sector has been playing an important role in enhancing Bangladesh economy. Women represent 85 percent of the total 30 million employees in readymade garment industry. A cross sectional descriptive study was carried out among the garments workers with the objective to assess the menstrual hygiene practices of female garment with structured questionnaire by workers. Majority of the respondents were within the age group of 18-23 years. This study showed that only $30.5 \%$ respondents were maintaining personal hygiene properly during menstruation and 12\% satisfied about their washing facilities in their working place. This study reflected different dimension in their reproductive life which were not upto the level. It should be improved for better standard. Further large scale studies needed to explore the real situation in this regard.
\end{abstract}

Keywords: Menstrual Hygiene practice, garment workers.

\section{Introduction}

Readymade garment sector has been playing an important role in enhancing Bangladesh economy. Women represent 85 percent of the total 24 million employees in readymade garment industry. Bangladesh is a society that has traditionally been characterized by very early marriage and child bearing when this is a period of physiological, emotional and intellectual development. The main objectives of this research were to identify knowledge and behavior of garments workers about menstruation. During the transition to adulthood, lack of knowledge and awareness about reproductive organs, physiological changes, or sexuality can promote psychosocial stress. About 34 million adolescents (10-19 years old) constitute $21 \%$ of total population of Bangladesh [1]. This is particularly so for girls, who also face gender discrimination. In most cases, their mothers are the only source of information. Most girls perceive menstruation as disgusting and as a curse [2]. Female garments workers are also at higher risk of psychosocial stress because of gender discrimination [3]. There is a lack of knowledge and awareness among female garments workers about health issues and problems like puberty, menstruation, physical changes in the body, reproduction, contraception, pregnancy, childbearing, reproductive tract infections, sexually transmitted infections (STIs), and HIV. A study conducted in Madras city revealed that 42 percent of the college and 34 percent of the school-going students reported problems during menstruation. The problems included headache, stomach pain, excessive bleeding, and other vague or non-specific symptoms like lethargy and loss of appetite. Girls are left socially isolated without sufficient knowledge and skills to effectively navigate life's challenges [4] (Urban Adolescent Needs Assessment Survey in Bangladesh, BIED \& BRACU). Nearly two-thirds of those who had problems sought medical treatment. Although most of these are normal symptoms of menstruation among adolescents, these need to be mentioned particularly in the Indian context because most of the girls are not aware of this natural phenomenon. Maternal mortality among mothers aged 15-19 is also very high as compared to the among mothers in the 20-24 years age group [5].They are not aware regarding their menstrual hygiene so they use unhygienic clothes or sanitary kits. According to WHO the cingulate mean age at first marriage for female of Bangladesh in 1995, was 18.8 in rural and 21.6 in urban areas [6]. As they are to work long term in garment factory and there is inadequate and unhealthy environment of bathroom facilities they could not change their pads timely. So they cannot maintain good menstrual hygiene practice. Adolescent girls are vulnerable to reproductive health problems like spasmodic dysmenorrhoea, heavy menstrual bleeding, scanty menstruation, amenorrhoea, irregular menstruation, leucorrhoea, vaginal candidiasis, pruritus 
vulvae, etc. as they have very little access to information and health care. Consequently they face health risk in their future lives.

\section{Methods}

\section{Study design and sample}

This study was conducted to assess the menstrual hygiene practices of female garment workers of Meherun Apparels Ltd Malibag, Dhaka according to the following methodologies:

This cross sectional study was conducted at two garments, Meherun Apparels Ltd Malibag, Dhaka. Data were collected by face to face interview, by asking them questions as per the written questionnaire at the factory. The study populations were interviewed one after another without disturbing their routine works.

\section{Analysis}

Collected data were analyzed after thorough checking, cleaning, editing and compiling by using the SPSS (Statistical package for social science, version 24 for windows) software and scientific calculator. Continuous variables were recorded into categorical variable by creating groups. The data were presented in different Tables, charts. The data were presented in different tables in order to the variables. Frequency tables according to the variables.The test statistics was used to analyze the data is descriptive statistics and inferential statistic according to the demand of the study with 95\% confidence interval. Level of significance was set at 0.05 . Qualitative data were analyzed on the basis of themes.

\section{Result}

This was a cross sectional study, conducted in garment factory with the main objective of the study was to assess the menstrual hygiene practice among the female garment worker. A total of 200 patients were interviewed.

\section{Distribution of the respondents by practice of clean material and materials used for cleanliness during menstruation $\mathbf{n}=\mathbf{2 0 0}$}

Out of the total 200 respondents, most of them 139 (69.5\%) did not use clean materials and less than one third $61(30.5 \%)$ used clean materials during menstruation. Out of the total 200 respondents, most of them 157 (78.5\%) had used old cloths and 41 (20.5\%) had used sanitary pads for maintaining cleanliness during menstruation.

Table 1. Distribution of the respondents by practice of clean material and materials used for cleanliness during menstruation

\begin{tabular}{|l|l|l|}
\hline $\begin{array}{l}\text { Practice of clean material } \\
\text { use }\end{array}$ & Frequency & Percentage \\
\hline Non clean material & 139 & 69.5 \\
\hline Clean material & 61 & 30.5 \\
\hline Materials used for cleanliness & \multicolumn{2}{|l|}{} \\
\hline Sanitary pads & 41 & 20.5 \\
\hline Old cloths & 157 & 78.5 \\
\hline Cotton & 2 & 1.0 \\
\hline
\end{tabular}

\section{Distribution of the respondents by menstrual hygiene practice}

Out of the total 157 respondents who practice using cloths, one fifth 117 (74.5\%) of them had washed with water \& soap, above one tenth $25(16 \%)$ with water only and below one tenth $15(9.5 \%)$ washed by soap \& savlon. Out of the total 157 respondents who practiced using cloths maximum of the respondents $137(87.26 \%)$ dried the cloth properly and more than one tenth $20(12.74 \%)$ of the respondents did not practice drying of cloths. Out of the total 137 respondents who dried the cloth properly, almost all of the respondents $125(91.24 \%)$ kept the cloth in safe place during menstruation. 
Table 2. Distribution of the respondents by menstrual hygiene practice

\begin{tabular}{|c|c|c|}
\hline $\begin{array}{l}\text { Practice of washing process of old } \\
\text { cloth } n=157\end{array}$ & Frequency & Percentage \\
\hline To wash with water only & 25 & 16.0 \\
\hline To wash with water \& soap & 117 & 74.5 \\
\hline To wash with soup \& savlon & 15 & 9.5 \\
\hline To wash with water only & 25 & 16.0 \\
\hline \multicolumn{3}{|c|}{ Practice of proper drying of cloth $n=157$} \\
\hline No & 20 & 12.74 \\
\hline Yes & 137 & 87.26 \\
\hline \multicolumn{3}{|c|}{ Keeping the cloth in safe place $n=137$} \\
\hline No & 12 & 8.76 \\
\hline Yes & 125 & 91.24 \\
\hline
\end{tabular}

\section{Distribution of the respondents by associated symptoms during menstruation $\mathbf{n}=\mathbf{2 0 0}$}

Out of the total 200 respondents, most of the respondents $88(44.0 \%)$ did not face any problem, 84 (42\%) had lower abdominal pain, one tenth 21 (10.5\%) developed weakness and a few $7(3.5 \%)$ developed nausea and vomiting during menstruation.

Table 3. Distribution of the respondents by associated symptoms during menstruation

\begin{tabular}{|l|l|l|}
\hline $\begin{array}{l}\text { Physiological problems } \\
\text { during menstruation }\end{array}$ & Frequency & Percentage \\
\hline No problem & 88 & 44.0 \\
\hline Nausea \& vomiting & 7 & 3.5 \\
\hline Lower abdominal pain & 84 & 42.0 \\
\hline Weakness & 21 & 10.5 \\
\hline
\end{tabular}

\section{Discussion}

The study was carried out to describe the Menstrual Hygiene Practices of Female Garment Workers in Selected Garment Factory. The study was done to assess the menstrual hygiene of female garment workers.

The minimum age was 18 years and the maximum age was 47 years. Out of the total 200 respondents, most of them $139(69.5 \%)$ did not use clean materials and less than one third $61(30.5 \%)$ used clean materials during menstruation. Out of the total 200 respondents, most of the respondents $88(44.0 \%)$ did not face any problem, $84(42 \%)$ had lower abdominal pain, one tenth $21(10.5 \%)$ developed weakness and a few 7 (3.5\%) developed nausea and vomiting during menstruation. most of them $176(88 \%)$ had not enough toilet facilities in their job places and only more than one tenth 24 $(12 \%)$ had enough toilet facilities.

\section{Conclusion}

Female garments Workers are associated with a wide range of negative social and health consequences and contribute to rapid population growth. This study showed that more than half respondents had not used clean material during menstruation. More than half of the respondents did not have any physical sickness during menstruation. But among rest of them majority felt lower abdominal pain, one tenth felt weakness and few felt nausea and vomiting. Maximum respondents were satisfied for enough toilet facilities in their job place and most of the respondents got support from guardian or authority.

\section{Acknowledgement}

I am extremely grateful to my respected teacher Assistant Professor Dr. Md. Shafiur Rahman for his continuous support and scholarly guidance despite his busy schedules. Without his valuable 
advices, constructive suggestions, passion and whole-hearted co-operation, I could never have completed it in time.

I express my sincere gratitude to Prof. Manzurul Haque Khan, PhD, Program in charge MPH $(\mathrm{OEH})$ and Dr. Irin Hossain, Lecturer, Department of Occupational and Environmental Health for their valuable advices, constructive suggestions and support to me regarding the whole task of the thesis.

I express my profound thanks to the Managing Director of Meherun Apparels, Malibag Chowdhury Para, Dhaka. At the same time I would like to extend my sincere thanks to all the respondents of this study for their kind participation.

\section{References}

[1].Acharya Dev Raj, Bhattarai Rabi, Pobalan Amuda, van Teijlingen, Edwin R, Chapman Glyn (2010) on Factors associated with teenage pregnancy in south Asia in Health science Journal, vol 4, issue 1.

[2].BRAC Annual Education Report, (2006).

[3].Gillespie Stuart on Improving Adolescent and Maternal Nutrition: An Overview of Benefits and Options (1997), papers no. 97-002.

[4].Rao.A.R. on "The Need and Challenge of Adolescent Health." Health for the Millions. May-June, (1995).

[5].Sharma A; Verma k; Khatri S. kannan A on Pregnancy in adolescent: a study of risks and outcome in Eastern Nepal, (2001); vol 38; pp 1405-1409.

[6].WHO Adolescent health report on Bangladesh (2016). 